\title{
The Narration Project. Skiagraphic Reading of the Ecce Homo Chapel at the Sacro Monte at Varallo ${ }^{+}$
}

\author{
Federico Manino ${ }^{1}$ and Ursula Zich ${ }^{2, *}$ \\ 1 Architect, 10126 Torino, Italy; federico.manino@gmail.com \\ 2 Politecnico di Torino, Dipartimento di Architettura e Design, 10125 Torino, Italy \\ * Correspondence: ursula.zich@polito.it; Tel.: +39-011-090-4364 \\ + Presented at the International and Interdisciplinary Conference IMMAGINI? Image and Imagination \\ between Representation, Communication, Education and Psychology, Brixen, Italy, 27-28 November 2017.
}

Published: 24 November 2017

\begin{abstract}
The Sacri Monti are devotional complexes whose chapels are structured as a support for the 'sequela Christi' meditation. We examine the relationship between the shadow drawing and the chapel narrative content, in particular its temporal moment. The reading of signs-painted shadow outlines-allows the analysis of a virtual reality in which the variable natural phenomenon is removed from the artwork, but returns to it as crystallized representation. The integrated reading shows the frescoes light as a chapels project strategy element. The use of light appears as an additional element aimed at achieving the expectations needed for greater illusion, to induce the spectator to be participating in the 'sequela Christi'.
\end{abstract}

Keywords: visual narration; virtual reality; skiagraphic reading; architectura picta

\section{Introduction}

This contribution analyses the light rôle as project strategy element in the frescoes realization of a place. In particular we examine the relation between the light representation and the iconographical content.

Indeed, the light can be used like graphic tool to guide the look in the pictorial space exploration, but can become itself an element for iconography understanding. In particular the painted shadow tracing is the only tool in the hands of painter to explain the time when the represented episode takes place.

The iconographical sources knowledge and the narrative elements analysis guide the survey of the representation graphic-metric aspects. Understanding the project aim with which the frescoes are realized allows to verify the real adhesion with the reference narrative texts. Consequently, the different light beams representation can be brought back to the story and emotion reasons.

Employing as case study the Sacri Monti chapels, the survey analyses the Ecce Homo one at Sacro Monte at Varallo, selected because of its significance.

\section{Materials and Method}

The Sacri Monti are devotional complexes [1] whose chapels, starting from the second half of the sixteenth century, are setted according to a progressive path: the story of the life of Christ or of a saint, or alternatively the succession of a devotional practice, like the Via Crucis or the Misteries of the Rosary.

The chapels are configured as a support for the new meditation forms of 'sequela Christi', like for instance the St. Ignatius of Loyola's religious exercises, that require the 'composition of place'. Consequently, the attention to the figurative datum, particularly the Holy Scriptures adherence, guides the chapels staging. Moreover, to allow an emotional attendance of the spectator with 
everything represented, a set of elements are put in place [2] to create the necessary expectations for the illusionistic enjoyment of the work [3] (pp. 206-207). Inside the stage we consequently perceive the merging of arts-picture, sculpture and architecture-to make a single image, on which the pilgrim will develop the interior prayer. Moreover, the grille presence prevents to spectator from verifying the actual reality of the stage [4] (pp. 196-199) and places him near the viewpoints provided by the frescoes. Thereby the boundary between three and two-dimensional elements disappeares and, thanks to the vestibule that isolates the pilgrim from the external world [5] (p. 446), the spectator finds himself de visu with the represented event.

At Varallo, as a result of the Council of Trent-that requests sacred images control-and particularly after the Pope's Sistus V decree in 1587-that assigns the interventions direction to Novara bishop as apostolic delegate [5] (p. 432) - the bishop Bascapè reorganizes the Sacro Monte. He destines the Mount upper part chapels to the story of the Passion and makes a synthesis of four Gospels on the basis of different texts, such as the Meditationes vitae et passionis Christi attributed to St. Bonaventura [5] (p. 441). In particular great project engagement takes the Pilate Palace building, that gathers the chapels connected to Pontius Pilate character and that is configured both as a container and a scenery [5] (p. 456) (Figure 1).

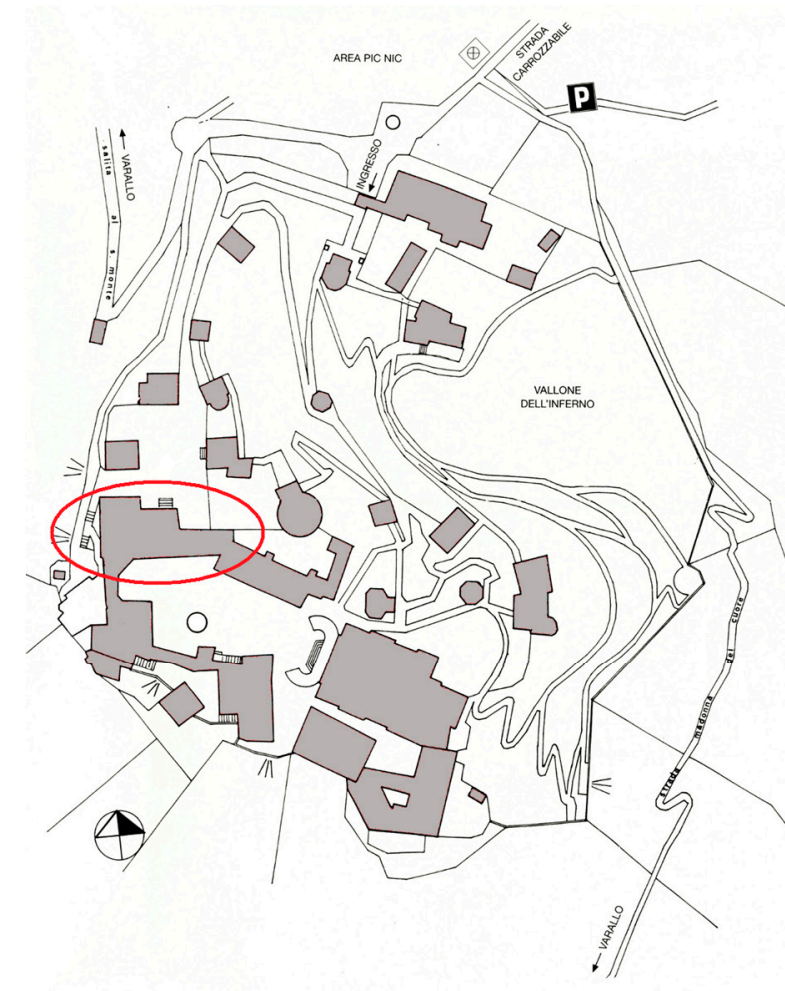

(a)

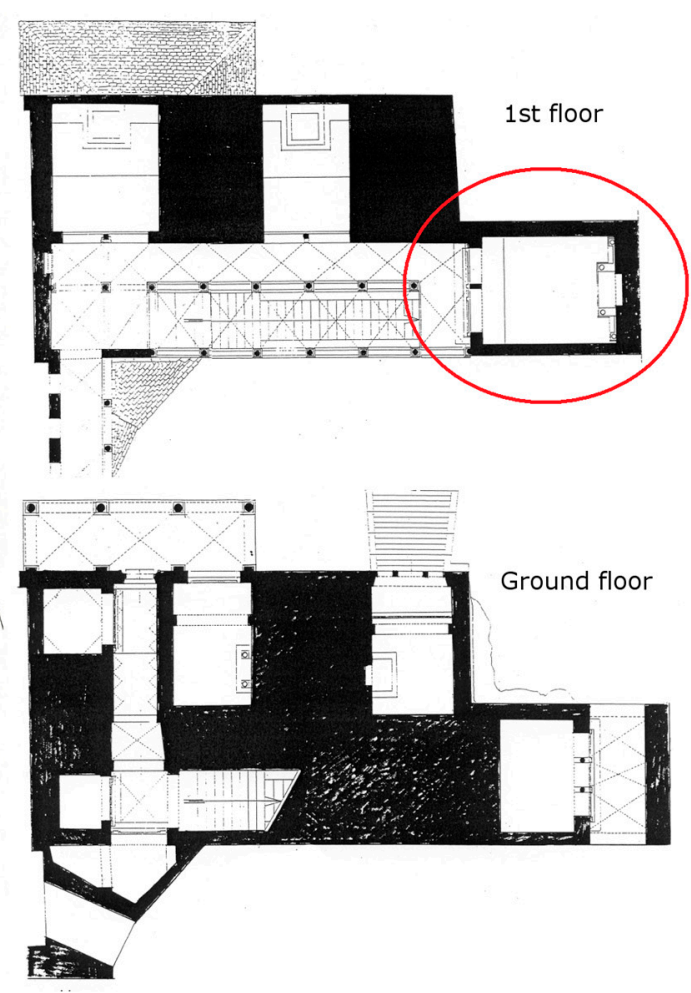

(b)

Figure 1. The context of the Ecce Homo chapel: (a) The Sacro Monte at Varallo with, in evidence, the Pilate Palace (elaboration from [16]); (b) The Pilate Palace with, in evidence, the Ecce Homo chapel (elaboration from [17]).

Inside this complex the first realized chapel is the Ecce Homo. The statues are modeled by Giovanni d'Enrico and the frescoes are painted by Morazzone between 1608, date of the Bascapè's order, and 1621, date of the grille insertion. This chapel moreover is the first to be placed into architectural perspective and to introduce into the stage the elements placed outside it [6] (p. 113). The Bascapè's order text, that describes the requested iconography, is unfortunately mutilated. It doesn't appear therefore any temporal information, but it's possible to assume its existence, because the document follows the topoi of contemporary meditation treatises [5] (doc. 8 p. 490) [7] (doc. 25 pp. 287-288) (Figure 2). 

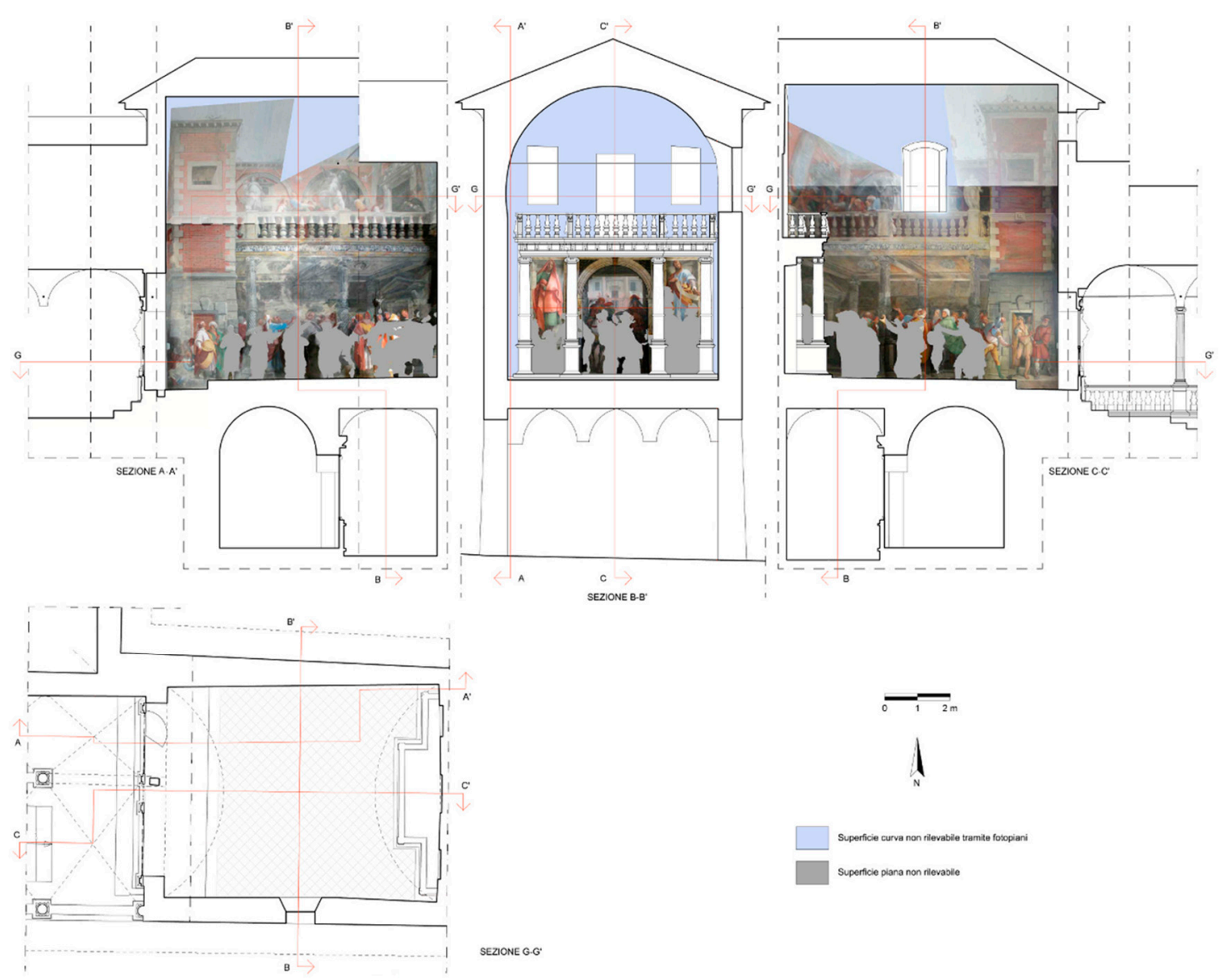

Figure 2. The Ecce Homo chapel survey (elaboration from [8]).

We procede to an integrated reading of the chapel, considering the project sources for his ideation and the catechesis purposes according to which it was realized. We analyse consequently the scene iconography, to deduce the represented events and places, as well as their narrative connections.

After that we make a graphic-metric survey of the light, both virtual and real, in the chapel. On the basis of frescoes metric survey and their perspective restitution [8] we proceed to the analysis of the painted shadows, distinguishing their various kinds. So, we identify the light sources, both virtual and real, and we analyse the connections, specifying coexistences, overlaps, valences and meanings. This reading is based on the conceptual tools of the sixteenth and seventeenth century skiagraphy, to get to an analysis as close as possible to the original project.

Finally, iconographical and skiagraphical reading results are compared, to add another element to the comprehension of project strategies-both technical and figurative content-subtended to the chapel staging. In particular we display the relations between the two readings (Figure 3). 


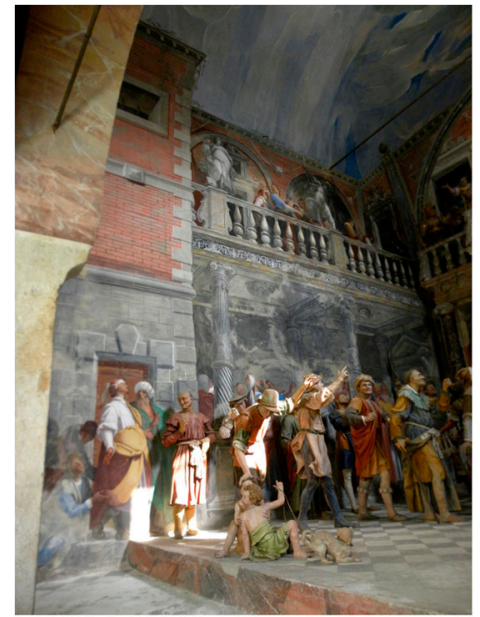

(a)

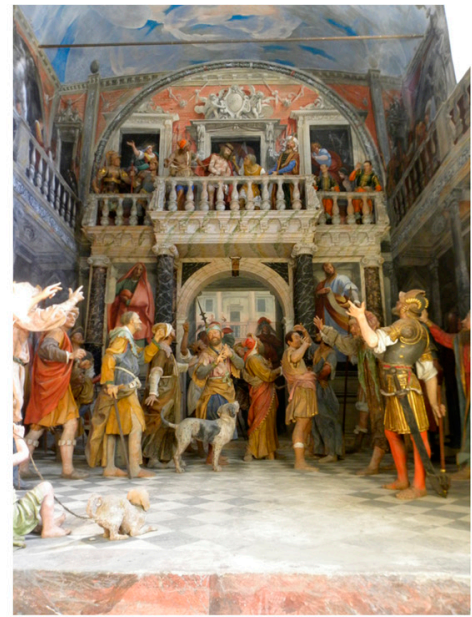

(b)

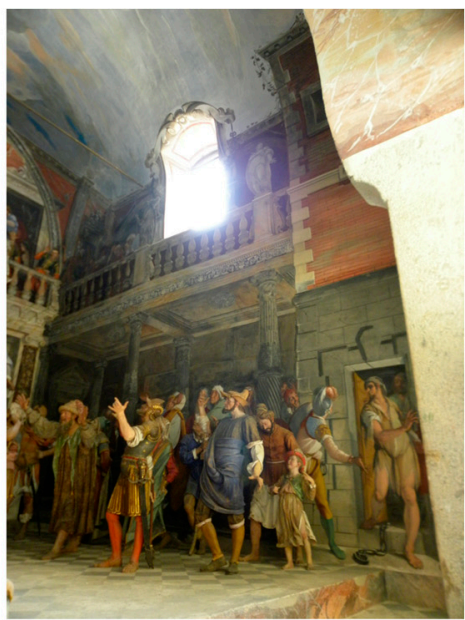

(c)

Figure 3. The three painted walls: (a) The left wall; (b) The front wall; (c) The right wall.

\section{Discussion}

Within the Ecce Homo chapel [9] (pp. 150-153), several episodes are represented, those of "Crucifige!", the Barabbas' release and "Ecce Homo". The simultaneous representation of distinct episodes, although considered insuitable by late-sixteenth-century treatises, had already taken place on Sacro Monte in the Ascent to Calvary chapel, painted by Morazzone himself [5] (p. 449). Also, within the chapel, a topomimetic element is placed-the Ecce Homo arch-to put the scene in a specific place-the Painful Way first station in Jerusalem [10] (p. 44).

In the scene, the reading of different episodes is spatially guided by some sculptural groups and painted architectural elements. As a matter of fact, the spectator is introduced to the scene by a statuesque group of bystanders on the far left, where an old bald man emerges, turned to the pilgrim. From here the spectator's eye passes to the "Crucifige!" group, which occupies the whole first level of the architectura picta and is composed of various characters, among which we can recognize the high priests Anna and Caifa. Following the indication offered by facing up statues hands and faces, the look moves to the second level on the "Ecce Homo" episode, the compositional fulcrum of the entire chapel with the characters of Jesus, Pilate, of his servants and of some Roman soldiers. At this point, without finding any significant indicator element, the spectator's attention extends to the architectural context in which the various episodes are placed. Continuing to read the scene clockwise, the spectator beholds on the far right the episode of Barabbas' release, caused by the choice between Jesus and Barabbas himself.

Following the Meditationes attributed to St. Bonaventura, the "Crucifige!" is pronounced in the same place on two different occasions, one in front of the choice between Jesus and Barabbas, the other after Pilate's expression "Ecce Homo". Therefore, the statuary group of "Crucifige!" is a junction element in the narrative reading of the chapel, being referable to both the episodes of the release and that of "Ecce Homo", which are temporally distinct but conceptually linked episodes.

The position of the "Crucifige!" group within the scene further shows his duplicity. In fact, the statues of the "Crucifige!" are at the same level of the Barabbas' release episode, in opposition to the group of "Ecce Homo" that is at the second level, while the release is placed in a different architectural context-the towers, symbol of the prison-with respect to arcades and terraces, symbols of the palace, where one finds both "Ecce Homo" and "Crucifige!". This last divide is also validated in the perspective restitution, as noted in [8], by the fact that the elements of the towers are not consistent with those of the adjacent arcades and terraces and that the design of the towers themselves has not useful elements for defining the chosen vanishing point, unlike the remaining frescoes.

Lastly, we point out that the towers are not characterized by a clear division into two levels, which on the contrary is present in the remaining illusory architecture. Therefore, these architectural 
elements, such as the facing up hands and faces of the "Crucifige!" characters, allow the spectator's eye to climb to the second level of the scene where the "Ecce Homo" episode is depicted.

\subsection{Real Light Sources Analysis}

There are three points where the light can go into the chapel: the first one is the grille (with a size of about $2.00 \times 5.00 \mathrm{~m}$ ) from where the spectator can look in, the second one is the window in the southern wall (with a size of about $2.10 \times 1.40 \mathrm{~m}$ ) visible by the pilgrim on his own right, while the third light source is a bull's eye (with a diameter of about $0.90 \mathrm{~m}$ ) placed in the wall above the grille.

These three openings are three different possible direct light sources, that come into play in different times of day. The presence of the light beam into the chapel, nevertheless, contradicts the frescoes illusion. In fact, in a snapshot vision, when the direct light hits the chapel walls, the spectator recognizes the presence of the pictorial surface, while in a longer time interval the change in the direct solar light inclination contradicts the fixity of painted shadows. Therefore, the openings in the chapel, necessary for the stage lighting and for the reading of frescoes, produce at certain times of the day incongruous beams with respect to staging (Figure 4a).

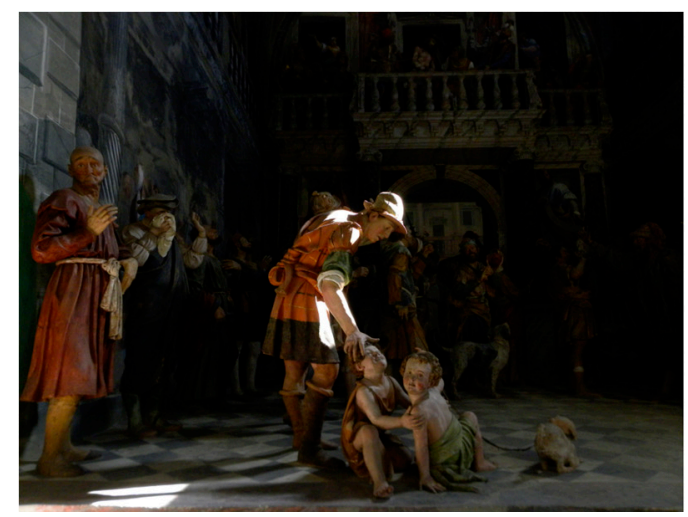

(a)

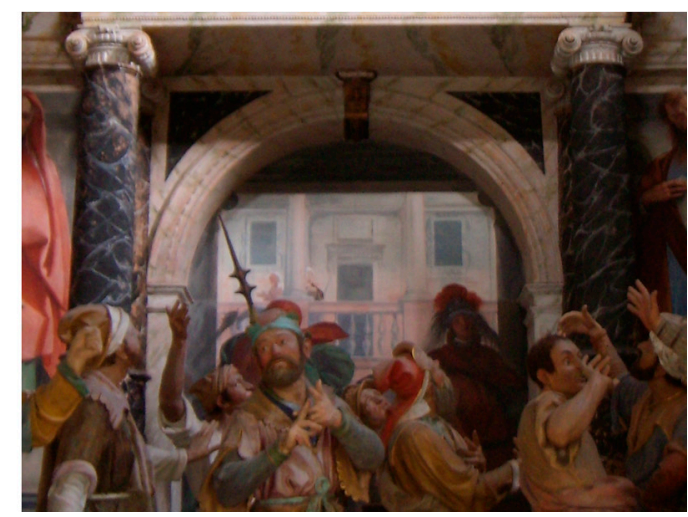

(b)

Figure 4. Real light versus virtual space: (a) A real light beam that generate an incongruous shadow in the architectura picta; (b) The real cast shadow of the arch is contradicted by the virtual space of the pictorial surface.

The reading of frescoes in illusory sense is possible therefore only when the different beams don't hit the painted walls that are visible from the grille. This particularly happens when the sunlight enters the chapel in an indirect way or, more frequently, when it hits the frescoes by reflection. In this last case, reflection can happen inside the stage - when the direct sun-light hits the floor or the wall above the grille-or outside it-when the light meets the vestibule floor. The presence of the Scala Sancta portico, as vestibule in front of the Ecce Homo chapel, allow the sun-light coming in through the grille, even if direct, doesn't hit the frescoes. Therefore, regarding the control of light coming in through the grille, the Ecce Homo chapel becomes the model for all the Pilate Palace chapels, where the grille is the only real light source of the stage, always constant in direction, even if not in intensity.

The Ecce Homo chapel major axis is oriented east-west and so the window is facing south. The general chapel shadow scheme consequently corresponds not only to the skiagraphic organization within the chapel, but refers to astronomic orientation of the sun. In this, the Ecce Homo chapel differs from other chapels of the Pilate Palace, because its reference system of virtual sun-light is clearly absolute, bound to the real astronomical phenomenon, and not relative to the sole position of its openings (see for instance in the Pilate Palace the Christ presented for the first time to Pilate chapel, where the virtual sun-light source is placed near the grille, i.e., in the wall facing north). 


\subsection{Shadows Representation}

The chapel under examination is characterized by a different representation of shadows depending on whether its surface geometry is complex-architectura ficta and statuary-or prevailingly level. Therefore, that part of the chapel end wall, that contains the "Ecce Homo" group, can be analysed separately from all other surfaces.

The chapel floor and the architectura ficta supporting the "Ecce Homo" group escape, like the statuary, any pictorial treatment of shadows. Therefore, there are only shadows produced by real light sources on these surfaces, even if not always consistent with the pictorial representation. For instance, the arch on the front chapel wall produces a cast shadows on the pictorial surface that simulates an opening and, therefore, the real shadows contradict the virtual space (Figure $4 \mathrm{~b}$ ). The absence of shadows representation, in addition to probable issues of pictorial execution simplicity, is perhaps even related to the will to emphasize the elements characterizing the two chapel scenes, "Ecce Homo" and "Crucifige!". Indeed, the statues, that make up the two groups, and the topomimetic element of the arch form the supporting structure of the scene from a narrative point of view, while all the other pictorial elements are only an addition. This narrative self-sufficiency manifests itself, as well as a different skiagraphic treatment, also with the incongruous insertion of a wreath inside the pictorial representation, to emphasize the crossing between the real chapel front wall and its barrel-vault.

On the contrary, the other chapel surfaces present a pictorial representation of shadows. The general skiagraphic scheme of the chapel is structured so as to let recognize two distinct and complementary scene areas-one in the upper left of the spectator prevalently lighted and one lower right in shadow [11] (note 26 pp. 106-107) - generated by a light source placed at the top right. Nevertheless, in comparison with a general easy and consistent skiagraphic scheme, we see a proliferation of virtual light sources, only partially connected with the chapel real ones. In the pictorial representation, we observe hence the coexistence and, in some cases, the overlap of the shadows, generated by the different light sources. This coexistence can be brought back to the sixteenth century interpretation, according to which sun-light is assimilated to light generated by an artificial source, point-like and placed at a finite distance [11] (p. 62).

The representation of light rays' coexistence and hence of their shadows is particularly evident on the chapel lateral walls, at the painted towers near the grille. The two representations are complementary because the one on the left is enlightened from above through the window, while the one on the right remains in shadow. Nevertheless, both tower scarps are enlightened from the bottom through the grille, so generating shadows upwards on the right wall in shadow and producing an apparently contradictory shadow group on the enlightened left wall. In particular the string course on the left wall between the upper part in brick and the scarp below generates form and cast shadows consistent with the general lighting from above, and produces a cast shadow upwards, compatible only with a light source placed down at the grille (Figure $5 b, c)$.

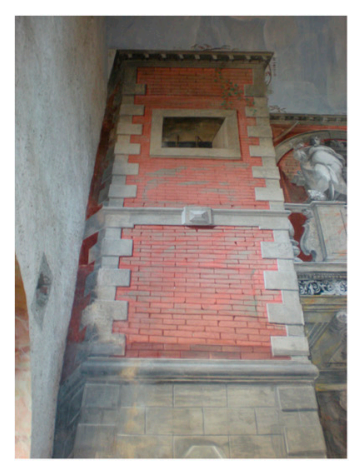

(a)

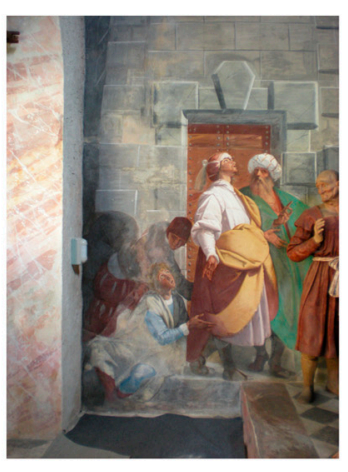

(b)

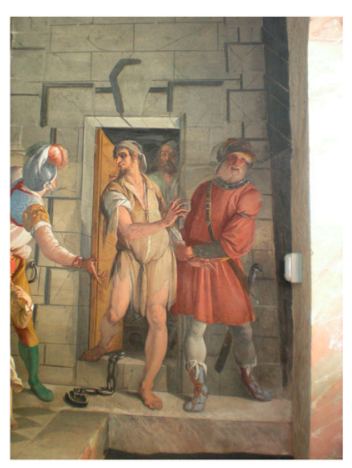

(c)

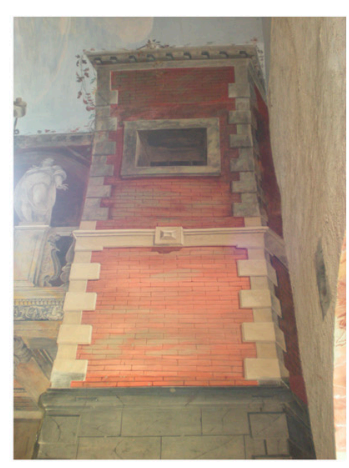

(d)

Figure 5. Light sources coexistence on the upper and lower part towers: (a) The upper part tower on the left wall; (b) The lower part on the left wall; (c) The lower part on the right wall; (d) The upper part tower on the right wall. 
Likewise, the two towers upper part are also enlightened by a light source approximate to the bull's eye one even though it does not coincide, because the virtual light source height is different between the two walls. Note, in particular, that in the left tower window, the two vertical rods of the grating generate different shadows on opening intrados, that can be brought back respectively to the light source approximate to the bull's eye one and to the one that enlights all the chapel left wall (Figure 5a,d).

The coexistence of several light sources, that cannot all referred to a real source, is found, as well as at the bull's eye, even at the chapel real window. This is indeed the major real light source of the chapel and, as aforesaid, is adopted as virtual light source in the most frescoes. Nevertheless, this is not the only light source that generates the two different areas of the scene, the one enlightened and the other in shadow. In fact, there is here a virtual source too, without a sun-light source: this light can be defined as a diffused light, although, in opposition to sixteenth and seventeenth century artistic praxis [11], its shadows don't always show vanished outlines. All the visible shadows on the architectura picta main front-above the "Ecce Homo" group and at the right terrace-are produced by this diffused light and therefore are part of the chapel general skiagraphic organization-i.e., with the virtual light source placed top right-but are indipendent of the window real light source.

The virtual shadow scheme generated by the window real light source doesn't always follow the same path. For instance, at the right wall, the balustrade representation in backlight presupposes a point source, while at the left wall the shadow drawing is repeated-perhaps obtained through cartoons - and requires a light source placed to infinity. This can be partly interpreted as the will to better harmonize on the right wall the insertion of the real window into virtual architectural space by the creation of a liminal space [12] (p. 59), described here by the light effect of backlight. On the contrary, the balustrade on the left wall is part of a more large area, placed in connection to the real window, characterized by a more bright colour tonality, in a kind of theatrical lighting at spotlight, that emphasizes the rôle of the characters on the left terrace: these indeed look from above to the real spectator, situated at the same height of the "Crucifige!" group, therefore making him an active protagonist of the scene [12] (pp. 92-94) (Figure 6).

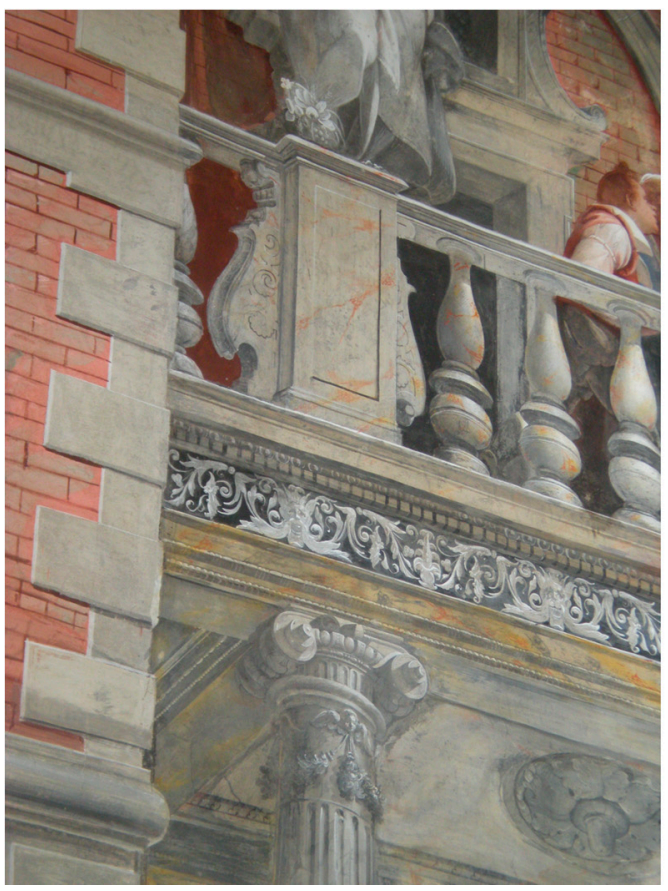

(a)

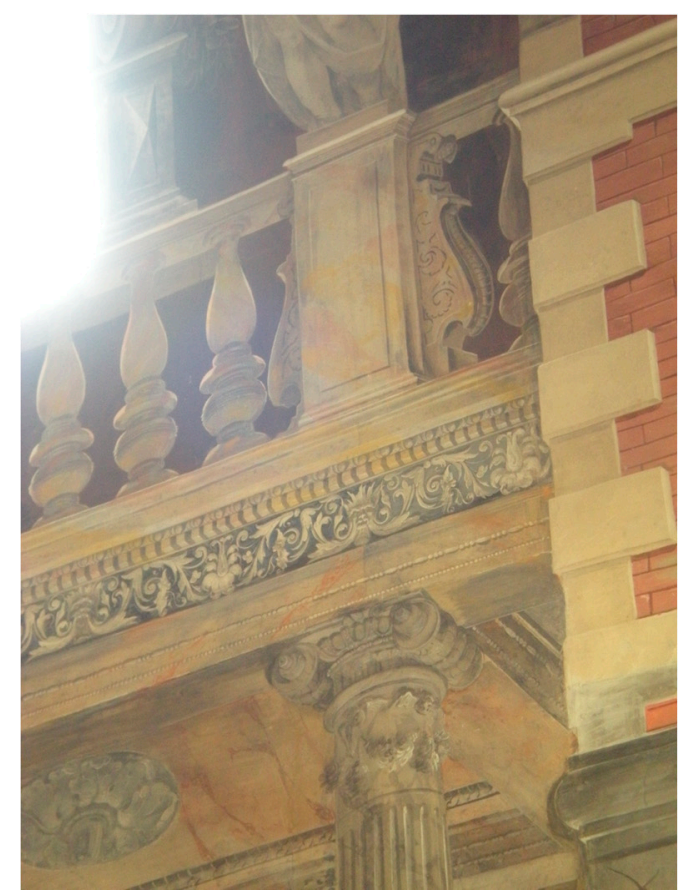

(b)

Figure 6. Brightness values and shadows coexistence on the chapel side-wall: (a) On the chapel left wall; (b) On the chapel right wall.

Coming down in the representation scale, we continue to find the coexistence of more light sources. This time however the shadow representation is used as a graphic detail element aimed at 
the plastic rendering of the represented elements. In fact, from the reading of the shadow outlines, we see a proliferation of light sources, redundant in comparison to the general economy of the architectural elements description. For instance, the capitals have a similar treatment: the shadows, in the crossing between a volute and other or even between a round and another of the same volute, vary the kind of the light source-placed at finite or infinite distance-and the position relative to the lighted element (Figure 7).

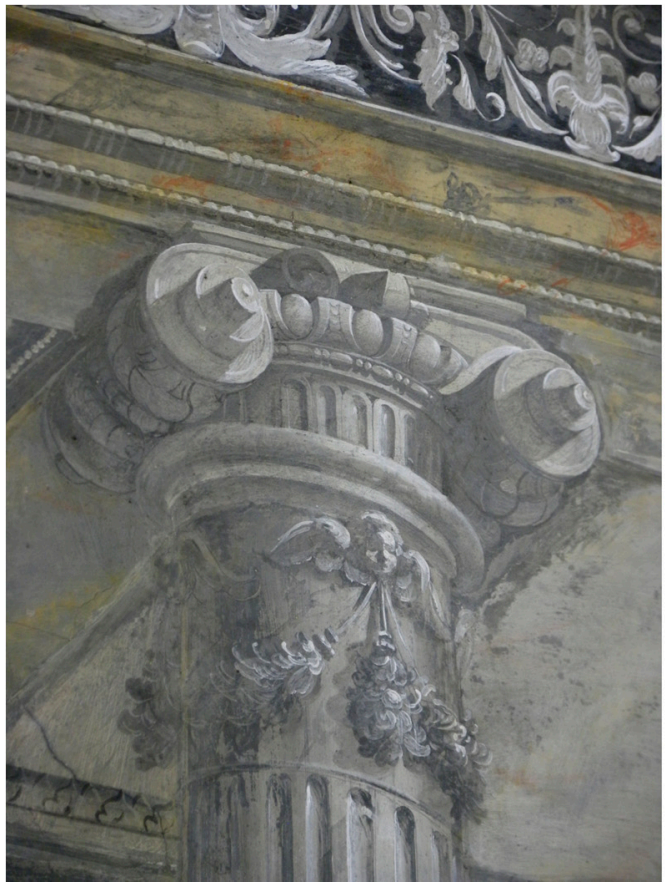

(a)

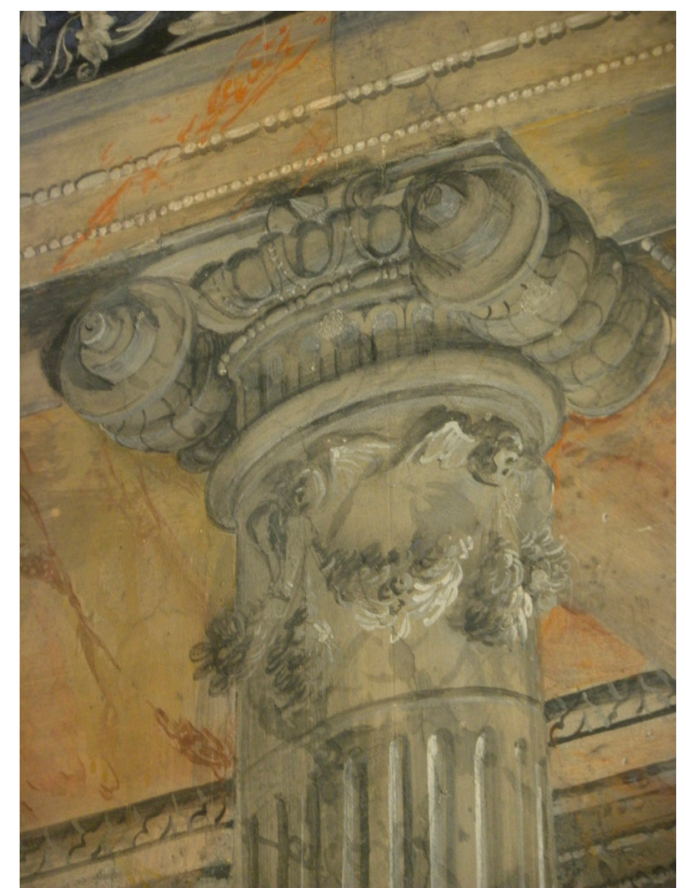

(b)

Figure 7. Shadows coexistence as the graphic detail element on the chapel side-wall: (a) On the chapel left wall; (b) On the chapel right wall.

In addition to these examples, where the shadows are drawed considering real or virtual light source, there are some fresco parts where the brightness values are used regardless of light sources [13] (pp. 320-323). The representation of these "shadows" is used to define in a univocal way the interpretation of the painted architectural shape and, in particular, to differentiate the various surfaces of the same architectural item. An example is the foreshortened vault above the left terrace, whose geometric shape is pointed out through a different brightness value at the intersection edges. Another case are the pyramidal section ashlars that adorn the string courses of the towers, where the different position planes of the ashlar are characterized by different brightness gradients. Moreover, always to make univocal the reading of the architectural shape, the brightness differences are used to create a separation between the elements at the close-up and those at background. An evident example are the capitals represented in the corners between the front and side-walls, where the black background doesn't have relation with the surrounding architectural structure, but have only the aim to emphasize the elements otherwise less readable due to real lighting absence (Figure 8). Another case are the lacunars of the two side-arcades, where the shape reading of the group columnentablature-lacunar is made easy by use of the different brightness gradients, also with the continuity of the level surfaces, to show up by contrast the different architectural components: in particular the different brightness relations are overturned between one wall and the other, in order to mantain the general subdivision of the scene between lighted and shadow area. Likewise, the use of brightness values is adopted also in replacement of the correct geometrical representation of the shadows. In fact, the form shadow, that points out the geometry of the columns shafts, changes its dimensions depending on the image context where the shaft portion is placed.

From this first investigation of the painted shadows in the chapel, we can find three different groups, each one connected with own light source. In fact, in addition to the painted shadows for the 
architectura picta texture, we can distinguish three main light sources: a source placed at the real window, the sources group connected with the rear-wall openings and, for last, the virtual diffused light placed on up to right.

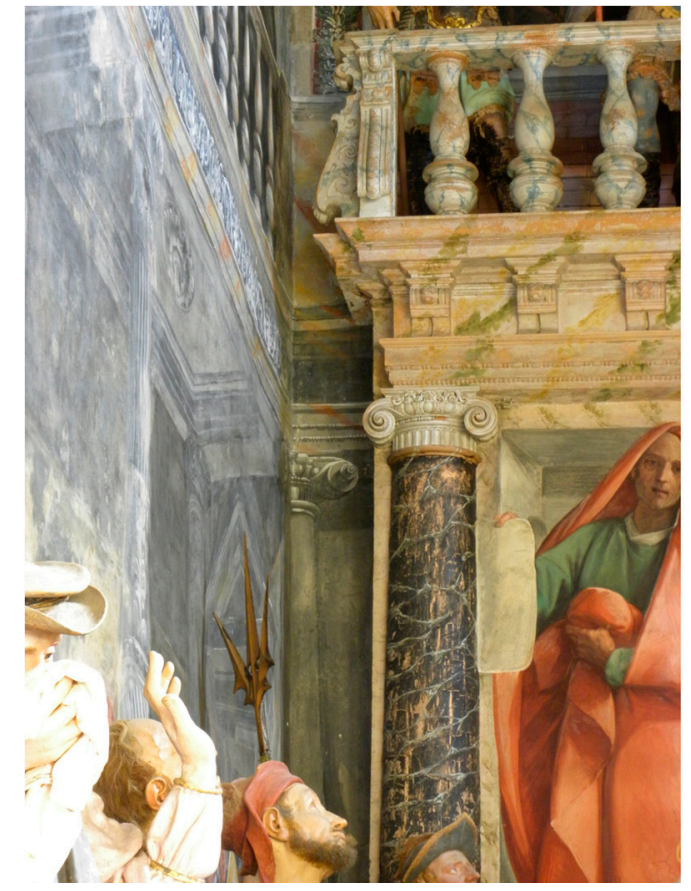

(a)

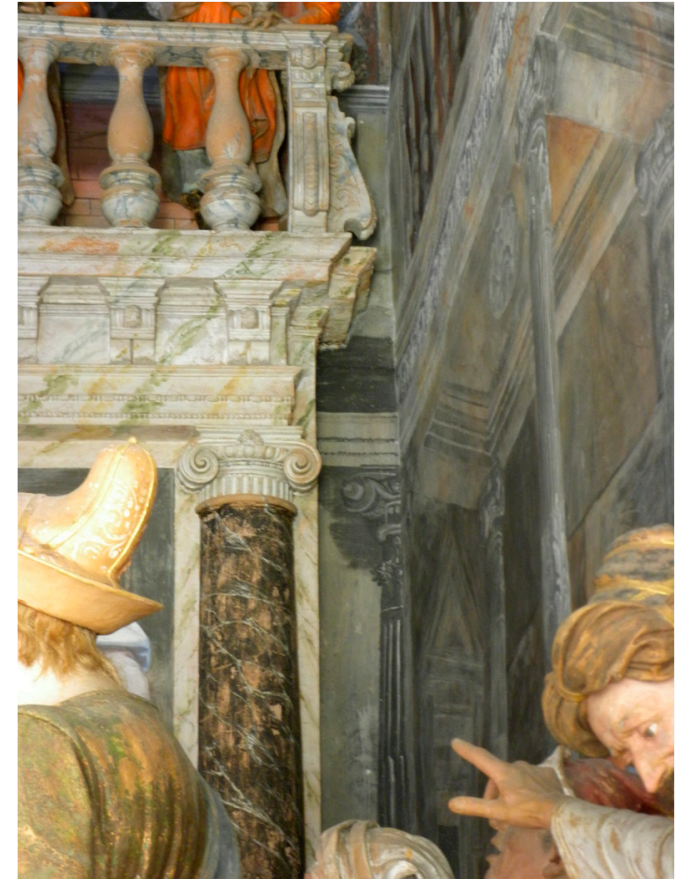

(b)

Figure 8. Brightness differences are used to create a separation between the elements at the close-up and those at background: (a) On the chapel corner between left and front wall; (b) On the chapel corner between right and front wall.

This coexistence of the light sources, both real and virtual, may appears chaotic, but assumes an own motivation, if we compare this skiagraphic reading with the scene iconography. In fact, the coexistence of more light sources can have a parallel with the simultaneous representation of different episodes. In particular every narrative episode is lightened by its own light source: the "Crucifige!" refers to the real window, the Barabbas' release to rear wall openings and at last the "Ecce Homo" to a virtual diffused light.

\subsection{Perspective Restitution}

Since the chapel architectura picta is represented on the basis of a geometric-perspective construction, we can do a metric check of those painted shadows whose outlines make possible to determinate the light source. The perspective restitution therefore focuses, on the right wall, on the shadow over the terrace, while, on the left wall, it focuses on the one inside the arcade (Figure 9).

This latter is traced on the flat surface of the left wall and has, in the perspective restitution, an outline slant of about $20^{\circ}$ with respect to the horizontal plane. Its outline, moreover, appears to be detached a few centimeters from the edge of the entablature generating it. Such detachment seems to be due to the lack of a direct correspondence in the crossing between the entablature form shadow and the relative cast shadow, while an inserted painted column hides this crossing.

The light beam that gives rise to the above shadow, both in the painted version and in the projectively correct one, in the perspective restitution is crossing through the real window-space. Therefore, we see how the shadow drawing takes into account, also from a metric point of view, the presence of the chapel real light source, following some treatise suggestions that the painter must depict the shadows according to the windows layout of the environment in which he works [11] (note 6 p. 105). However, the shadow perspective restitution shows its inconsistency with respect to the virtual space of the architectura picta, because the light source is placed behind the buiding portion 
depicted on the chapel right wall. Hence it follows a contradiction in the illusory architecture design, since the architectura picta doesn't take into account the real window presence, and indeed, the latter is integrated in the fresco in a forced manner and little consistent with the context image. This contradiction is not immediately recognizable, because the approach to figurative content in the Sacri Monti chapels, mediated through the grille, implies an artwork parcelled vision [14].

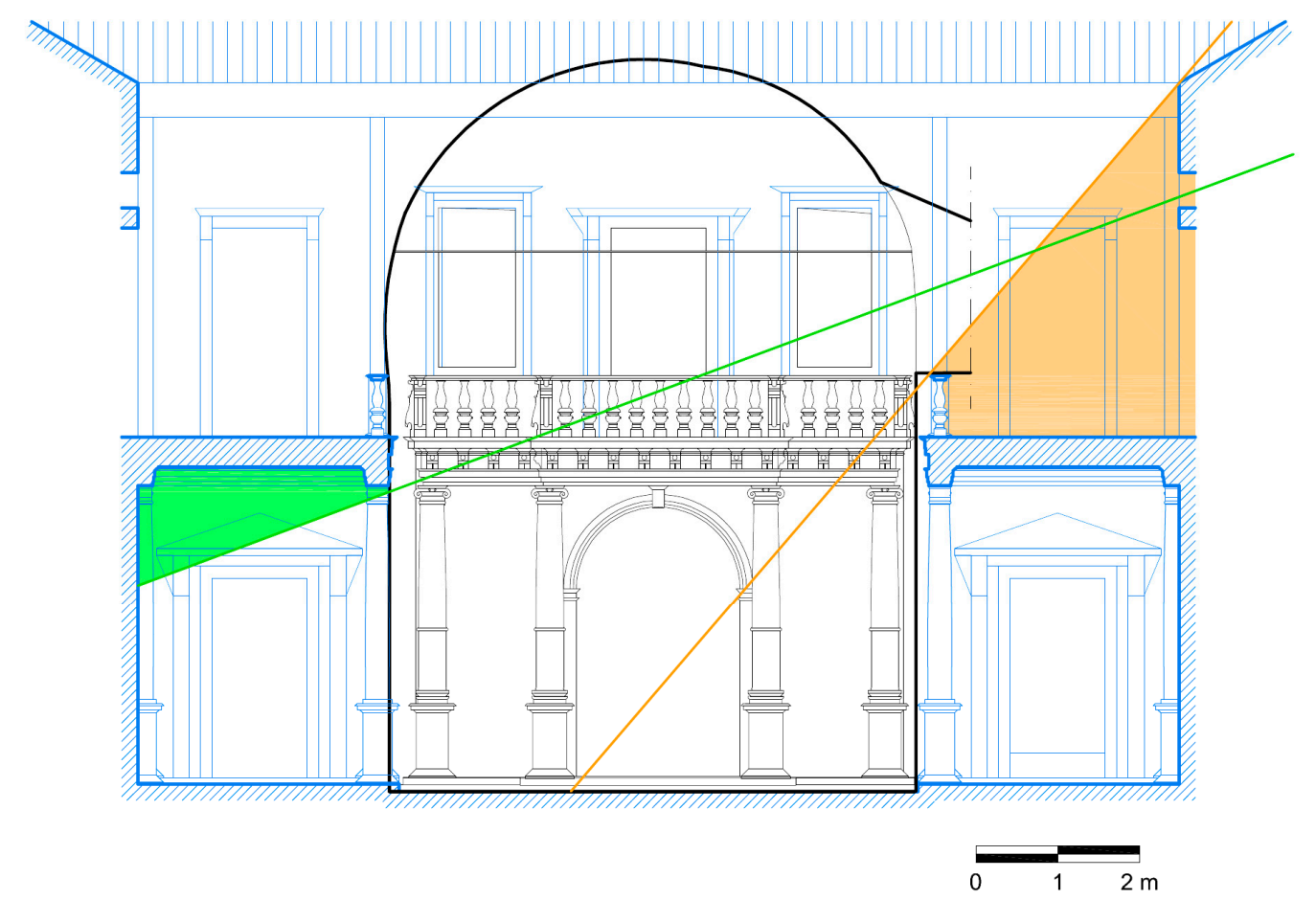

Figure 9. The shadows perspective restitution of the architectura picta front. By black there is the real chapel; by blue the architectura picta; by green the shadow slant in the left arcade; by orange the shadow slant in the right terrace.

In addition, it should be noted that the virtual light source corresponding to the real window is located in the space centre, in accordance with the sixteenth and seventeenth century treatises, which state that sun-light coming from a window is assimilated to a point source at the window-space centre [11] (p. 86) or, in alternative, to four point sources at each vertex of the window-space [11] (p. 79).

The shadow above the terrace painted on the right wall is represented from the angular edge of the architectura picta cornice to the wreath base-this wreath indicates the passage between the barrel vault and the chapel bottom wall. This shadow tracing develops on the barrel vault only, without invading other real surfaces. This shadow outline isn't shaded and therefore it seems to be represented more on the basis of figurative needs than on the basis of an actual correspondence with a diffused light source. Nevertheless, from the perspective restitution it is possible to obtain a slant of about $45^{\circ}$ with respect to the horizontal plane.

This slant is such that, by extending its outline, the shadow falls on the floor at the stage centre. Thus, a contradiction emerges, because the non-representation of the virtual light source isn't compatible with a scene view in the grille left portion, i.e., in correspondence with the virtually enlightened part. Nonetheless, this shadow slant is not contradicted by the architettura picta, unlike the arcade shadow on the left.

As we have seen, the presence of more light sources is linked to the different episodes represented in the scene. However, the sun-light representation with different slants may seem strange if one of the iconographic sources used for the chapel didn't come to our rescue. In fact, the Meditationes attributed to St. Bonaventura places the different episodes in a narrative sequence, which has its correspondent in the chronological sequence underlying the shadow drawing. In particular, 
the "Crucifige!" comes before the "Ecce Homo", while Barabbas' release is presented as a parallel event.

It seems then possible, from the examination of the virtual rays' slant, to verify the relationship between the shadow drawing and the chapel narrative content, in particular its temporal moment. From the reading of Gospels, Passion events linked to Pilate should be placed on Friday before Easter, but it isn't possible to deduce the exact time of the episodes represented in the Ecce Homo chapel. However, following St. Bonaventura's Meditationes, we can place the first "Crucifige" scene during the first hour - that is between 6:00 a.m. and 9:00 a.m. - and the "Ecce Homo" in the third hour-that is between 9:00 a.m. and 12: 00 p.m. We can then compare the shadow slants painted in the chapel with the Varallo Sesia solar diagram (latitude $45^{\circ} 49^{\prime}$ N) [15]. Referring to the time of the year when Easter may fall (22 March-25 April), we observe a correspondence between the time representation of each episode and the time when this should have occurred. In particular the shadow outline slant referable to the "Crucifige!" is compatible with a time situation between 7:15 a.m. and 8:00 a.m.-i.e., by the first hour - while that of the "Ecce Homo" between 10:15 a.m. and 12:00 p.m. -i.e., by the third hour.

Thus, there is a temporal correspondence not only relative but also absolute between the image and its source, between the shadow drawing in the frescoes and the chapel narrative content.

\section{Conclusions}

From the integrated reading - both iconographic and skiagraphic-it emerges that the multiple light sources coexistence has a parallel with the simultaneous depiction of different episodes: each light source enlights a particular episode.

Moreover, the perspective restitution of painted shadows allows to detect the virtual light rays slant. So, there is a correspondence between the episodes narrative sequence and the chronological sequence underlyined by the shadow drawing.

At last, relying on the project sources, in particular the Meditationes attributed to St. Bonaventura, we find a possible correspondence between the time representation of each episode and the time when this should have taken place. In this way, a temporal correspondence is revealed, not only relative but also absolute.

This integrated approach, which takes into account both the narrative content and how it's represented, shows that likelihood and realism required by the religious commitment cannot just affect the characters and architectures reproduction, but can also express the visual reproduction of the time in where the represented episodes occur. The reading of signs-painted shadow outlinesallows the analysis of a virtual reality in which the variable natural phenomenon is removed from the artwork, but returns to it as crystallized representation. Therefore, the painted shadows presence takes shape of the aristotelic hic et nunc extrinsication and thus leads the pilgrim into his interior prayer, placing him at different moments of the various episodes. The use of light appears as an additional element aimed at achieving the expectations needed for greater illusion, to induce the spectator to be emotionally involved and to be participating in the 'sequela Christi'.

Thus, the results obtained from the study of chapel Ecce Homo become a further element to understand the design and communication strategies implemented in Varallo between the sixteenth and seventeenth centuries. More generally, this reading can be applied to all those chapels of the prealpine Sacri Monti, where the light component is part of the visual artwork realization in its narrative dimension.

Author Contributions: The authors have conceived and writed in coordinated way.

Conflicts of Interest: The authors declare no conflict of interest. The founding sponsors had no role in the design of the study; in the collection, analyses, or interpretation of data; in the writing of the manuscript, and in the decision to publish the results. 


\section{References}

1. Langé, S. Sacri Monti Piemontesi e Lombardi, 1st ed.; Tamburini Editore s.p.a.: Milano, Italy, 1967.

2. Zich, U.; Manino, F. Per un censimento del quadraturismo in Piemonte. Approccio metodologico ai Sacri Monti. In Prospettive Architettoniche. Conservazione Digitale, Divulgazione e Studio, 1st ed.; Valenti, G., Eds.; Sapienza Università Editrice: Roma, Italy, 2014; pp. 617-642, ISBN 978-88-98533-45-9, doi:10.13133.

3. Gombrich, E.H. Art and Illusion. A Study in the Psychology of Pictorial Representation, 1st ed.; Phaidon Press Ltd: London, UK, 1960.

4. Freedberg, D. The Power of Images. Studies in the History and Theory of Response, 1st ed.; The University of Chicago Press: Chicago, IL, USA; London, UK, 1989.

5. Gentile, G. Gli interventi di Carlo Bascapè nella regia del Sacro Monte di Varallo. In Carlo Bascapè Sulle Orme del Borromeo. Coscienza e Azione Pastorale in un Vescovo di Fine Cinquecento, 1st ed.; Tuniz, D., Zaccheo, G., Eds.; Interlinea Edizioni: Novara, Italy, 1994; pp. 427-476, ISBN 88-86121-37-7.

6. Brizio, A.M. Giovanni d'Enrico. In Congresso di Varallo Sesia, 1st ed.; Società Piemontese di Archeologia e Belle Arti: Torino, Italy, 1960; pp. 109-114.

7. Stoppa, J. Il Morazzone, 1st ed.; 5Continents Editions: Milano, Italy, 2003; ISBN 88-7439-076-9.

8. Manino, F. Dal Quadro Prospettico All'oggetto della Rappresentazione. Lettura Critica Dell'architettura Illusoria Nella Cappella Dell'ecce Homo al Sacro Monte di Varallo. Master's Thesis, Politecnico di Torino, Torino, Italy, 19 Decmber 2011.

9. Pomi, D. La Parola si fa Arte. Luoghi e Significati del Sacro Monte di Varallo, 1st ed.; Editoriale Jaca Book spa: Milano, Italy, 2008; ISBN 88-16-40834-0.

10. Langé, S. Esperienza del reale e spazio virtuale nell'iconografia della Passione. In Il Sacro Monte. Esperienza del Reale e Spazio Virtuale Nell'iconografia della Passione a Varallo, 1st ed.; Langé, S., Pensa, A., Eds.; Editoriale Jaca Book spa: Milano, Italy, 1991; pp. 7-46, ISBN 88-16-60121-3.

11. De Rosa, A. Geometrie Dell'ombra. Storia e Simbolismo della Teoria delle Ombre, 1st ed.; Città Studi Edizioni: Milano, Italy, 1997; ISBN 88-251-7201-X.

12. Shearman, J. Only connect... Art and the Spectator in the Italian Renaissance, 1st ed.; The National Gallery of Art: Washington, DC, USA, 1992; ISBN 0-691-09972-3.

13. Arnheim, R. Art and Visual Perception. A Psychology of the Creative Eye, 2nd ed.; University of California Press: Berkeley, Los Angeles, CA, USA, London, UK, 1974; ISBN 0-520-24383-8.

14. Francastel, P. Peinture et Société. Naissance et Destruction d'un Espace Plastique de la Renaissance au Cubisme, 1st ed.; Audin Editeur: Lyon, France, 1951.

15. Atlante Italiano della Radiazione Solare. Available online: http://www.solaritaly.enea.it/ StrDiagrammiSolari/X12Mesi2.php (accessed on 12 September 2017).

16. De Filippis, E. Guida del Sacro Monte di Varallo, 1st ed.; Riserva Naturale Speciale del Sacro Monte di Varallo: Varallo Sesia, Italy, 2009.

17. Debiaggi, C. Il palazzo di Pilato. Il Sacro Monte di Varallo 1992, 8, 6-9.

(C) 2017 by the authors. Licensee MDPI, Basel, Switzerland. This article is an open access article distributed under the terms and conditions of the Creative Commons Attribution (CC BY) license (http://creativecommons.org/licenses/by/4.0/). 